\title{
EL LEGADO CULTURAL DE LAS TORRES VIGÍAS COSTERAS DE MÁLAGA: ENTRE EL CONOCIMIENTO, LA PROTECCIÓN, Y SU CONSERVACIÓN
}

\author{
EduARdo AsEnJo Rubio
}

\begin{abstract}
RESUMEN
Este artículo es un estudio de las torres vigías de la costa en Málaga. Se ha realizado un análisis de sus valores patrimoniales, la protección desde el ámbito normativo, los problemas urbanísticos que genera su entorno, y la necesidad de conservarlas para evitar su desconocimiento.
\end{abstract}

\section{ABSTRACT}

This article is a research report on the watchtowers situated along the coast of Málaga. The aspects analysed herein arer cultural heritage velua, protection by legislation, problems concerning territorial planning in the surrounding areas and the necessity of attaching importance to these watchtowers in order to avoid disregard.

\section{LA IDENTIFICACIÓN DE LOS VALORES PATRIMONIALES DE LAS TORRES VIGÍAS COSTERAS DE MÁLAGA}

El reconocimiento de los valores patrimoniales de estas atalayas costeras pasa por la enumeración de cada uno de ellos, de tal forma que puedan extraerse las características que mejor definen su idiosincrasia, aunque previamente conviene introducir alguna reflexión, en relación con su protección.

Este legado cultural a pesar de poseer un representativo elenco de valores patrimoniales que podríamos calificar de tradicionales, junto a otros insertos en la tendencia más moderna de la tutela de los Bienes Culturales, interpretada como paisaje y territorio; en la actualidad, su estado de conservación es un pálido reflejo de su paso por la historia, y en absoluto responde al papel que jugaron desde el momento en que se integraron en este territorio costero. 
La protección en si misma es una medida que no impide que dichos valores puedan ser vulnerados; en cambio, si va acompañada de acciones en materia de conservación, y dinamización se salva un escollo principal, el olvido social al que está sometido este patrimonio ${ }^{1}$. Por lo tanto, hay que reivindicar no sólo una protección efectiva, sino también una protección física que impida el deterioro material de esta arquitectura defensiva, e inclusive devolverle su propia dignidad, en tanto en cuanto estos monumentos pueden constituir en un futuro nuestra carta de presentación para un determinado usuario. Entre otras razones, porque desde los años 60 del siglo $\mathrm{XX}$ algunas tarjetas postales de la Costa del Sol han construido y proyectado su imagen al exterior apoyándose en estos monumentos, casi siempre como evocación de su participación en la historia por parte de los municipios que tenían estas torres en su demarcación territorial.

Tampoco debemos olvidar que por ministerio de la ley, el decreto de 22 de abril de 1949 reconocía y protegía toda la arquitectura defensiva, inclusive aquella que se encontrara en ruina. No obstante, esta protección in extremis parecía más una medida propia de los inventarios, que precisan un conocimiento mínimo del bien antes de su desaparición, que una disposición pensada para garantizar un futuro más halagüeño a este significativo legado cultural. Y de hecho así ha sido, como tendremos ocasión de comprobar en el epígrafe sobre el paisaje, el entorno, y la problemática urbanística.

Por lo tanto, esta declaración genérica se justifica mediante un decreto ley, pero ¿dónde está la motivación cultural que justifique su protección? Aunque la ley no enumera de forma individualizada sus valores patrimoniales, lo cierto es que estos bienes declarados monumentos históricos artísticos detentan un conjunto de valores que justifican dicha categoría jurídica de protección. En el momento de su declaración, obviamente, el valor determinante fue el histórico artístico. Actualmente, a estas torres se le suman otros valores, como el tipológico, y paisajístico, por citar sólo algunos.

El valor histórico es el testimonio de unas peculiares circunstancias políticas que refleja la protección y definición de unos espacios fronterizos, una vez concluido el proceso de conquista. Por lo tanto, estos inmuebles desde una valoración contemporánea representan uno de los testimonios más relevantes de la cultura bajo medieval y moderna, en tanto en cuanto pueden considerarse marcadores territoriales jurìdicos, al mismo tiempo que elementos introductores de unas formas diferentes a las anteriores de apropiación del territorio, asociada a otros grupos culturales. A la anterior situación habría que unir otros

1. Este primer olvido se encuentra en la imprecisión cronológica, ya que para una gran parte de la sociedad son construcciones árabes, sin embargo, la mayoría de ellas se realizaron durante la Edad Moderna. 
acontecimientos que se produjeron a lo largo de la Edad Moderna, y muy especialmente durante los reinados de Carlos I, Felipe II y Carlos III, como fue la voluntad de controlar e impedir las incursiones puntuales, los arrebatos de la piratería berberisca por la costa, lo que llevó a la Corona a vertebrar todo este vasto territorio mediante un programa de construcciones defensivas, estableciendo una intensa y omnipresente vigilancia, al mismo tiempo que se facilitaba la comunicación entre ellas y las poblaciones cercanas.

Además, muchas torres vigías presentan la particular dualidad de estar asociadas a yacimientos arqueológicos, lo cual enriquece aún más su valor cultural, al constituirse en un magnífico escenario estratigráfico, sedimento de otras culturas precedentes y su forma de interrelacionarse e interpretar por parte de esas comunidades ese mismo espacio, y el territorio mas inmediato.

En cuanto al valor artístico, en este campo el estilo se define por dos factores, su forma, casi siempre austera, el sabio conocimiento, ejercicio y dominio de la tradición técnica y los materiales, la mayoría de las veces mampostería, y en ocasiones reforzada en las esquinas con despieces de piedra cortada a escuadra. Este estilo de frontera deja al descubierto la pureza de unas formas geométricas magníficamente proyectadas en un paisaje altamente vulnerado, especialmente desde los años 50 del siglo XX hasta la actualidad ${ }^{2}$. Sin embargo, no hay que olvidar que estas arquitecturas defensivas, y dada su ubicación en promontorios, en la playa o al borde del mar, tuvieron que estar tratadas en el exterior con algún tipo de revestimiento para proteger la fábrica. Tenemos varios ejemplos en los que se han conservado restos de revoco del muro asociado a decoraciones de carácter incisa, y una breve lectura permitirá acrecentar aún más este valor. La torre de Gudalmansa en Estepota, y la torre de la Cala del Moral o Torre Vieja en Mijas son los dos ejemplos que han mantenido parcialmente esa película ornamental. En el caso de la primera, se trata de una construcción cuyos orígenes pueden fecharse a finales del siglo $\mathrm{XV}$, posteriormente reformada. Nos interesa la decoración que se ha conservado en una de las caras, consistente en un cuadrado con un círculo inscrito. Se trata de una decoración incisa realizada sobre el mortero aún húmedo. (Fig. 1) Pero, ¿qué tiene de especial este ornamento parcialmente conservado? La cuadratura, la forma en la que se presenta ese círculo, cuyo cuadrado establece el principio y el final de la composición, un sistema cuyo pasado podemos rastrearlo en la arquitectura islámica, que como precedente cultural nos queda

2. Las intervenciones inapropiadas en los monumentos no deben juzgarse como producto del pasado, también en el presente se realizan auténticas tropelías, una de las últimas la intervención en el antiguo pavimento del patio de los Naranjos de la Catedral de Málaga. Es obvio que el concepto de antigüedad no forma parte del repertorio de ideas de los titulares del inmueble, que sólo buscan la absurda modernidad en un edificio que no se lo pide, que no lo requiere. 
bastante cercano. Las líneas que marcan ese cuadrado forman el escenario en el que se desarrolla la narración de otra forma, en este caso un sencillo círculo. Esta manera oclusiva de trabajar el muro ha sido característica de la arquitectura pintada en Málaga, especialmente en su primera gran etapa, como puede comprobarse en el inmueble n. 11 - 13 de la Plaza de la Constitución, toda una gran composición bajo la cuadratura definida por la propia arquitectura que actúa de soporte, y el horror vacui de la ornamentación que abunda el espacio. La iglesia de San Juan Bautista es otro ejemplo, cuyo esquema combinado de hexágonos quedan comprendidos bajo la línea que delimita y perfila el marco narrativo, en este caso una sucesión de figuras geométricas perfectamente trabadas. (Fig. 2 - 3)

En el caso del segundo ejemplo es aún más interesante si cabe por los restos conservados. Su origen pude fijarse a finales del siglo XV, aunque las reformas que se produjeron a mediados del siglo XVIII le dieron la fisonomía que conserva en la actualidad. En la parte superior de los espolones oblicuos u hornabeques situados en el dorso de la torre se han conservado dos tipos de decoración, un jarrón con hojas sueltas, y el característico cajón inciso entre verdugadas de ladrillo, también incisos. Del jarrón al tratarse de un elemento aislado poco podemos decir, simplemente que se trata de una forma rucia, mientras que el otro elemento decorativo se inserta en la tradición de las fachadas pintadas de la ciudad de Málaga, a finales del siglo XVII y comienzos de la siguiente centuria, como puede comprobarse en el exterior del Santuario de Nuestra Señora de la Victoria, en la iglesia del Sagrario, en la de los Agustinos, así como en la arquitectura civil, en el inmueble n. 5 - 7 de calle los Mártires. No quedan restos de policromía, pero es seguro que los ladrillos estarían pintados en rojo de almagra, tonalidad habitual de ese material.

De ambos ejemplos puede extraerse una misma conclusión, que la decoración de la arquitectura defensiva fue una realidad, aunque sólo podamos aventurarlo hasta el momento en dos ejemplos, pero lo cierto es que esta tipología arquitectónica podía contener motivos ornamentales muy similares a los de la arquitectura civil y religiosa.

El valor tipológico a simple viste enriquece el paisaje, lo informa de variedad, lo determina, irrumpiendo aún más el contrastado contorno de la costa, al dejar la impronta inventiva del ser humano. Torres cilíndricas, rectangulares, de pezuña o con forma de herradura son las plantas más habituales que encontramos, perfectamente colocadas, con una altura que oscila entre los 10 y los 12 metros. El interior suele estar dividido en dos plantas, siendo la superior el espacio destinado al hogar, con la chimenea y la alacena. La presencia de uno o dos ventanales permite su iluminación y ventilación. La azotea solia contar con un pretil, y a veces torretas provistas de aspilleras, cubiertas con teja árabe. (Fig. 4 - 5) 
En cuanto al valor paisajístico, las fotografías pertenecientes al archivo Temboury constituyen documentos de gran valor en relación con el cambio espacial que han experimentado estas arquitecturas defensivas. El abandono de una gran parte de las torres vigías en un paisaje salpicado de acantilados, ensenadas y playas de prolongadas dunas, cuya visión se pierde en el horizonte, las ha convertido en imágenes hieráticas y ensoñadoras, ecos de un período histórico cerrado. Sin embargo, la vorágine urbanística surgida a partir de los años 60 del siglo XX, aún vigente, ha dejado desprovista a estas atalayas costeras de uno de sus valores patrimoniales más representativos, y que le daban carta de naturaleza, la libertad de su contemplación originaria, acotándola en absurdos espacios que las encorsetan, cuando no las ocultan o enmascaran, de tal forma que estos monumentos en su gran mayoría se han visto obligados a establecer otras relaciones bien diferentes con su entorno ${ }^{3}$. Se pueden diferenciar dos claras posturas; una, la vanalización del monumento al quedar reducido a mera comparsa de las promociones urbanísticas surgidas en su entorno; dos, la puesta en valor que implica un estudio y organización espacial, y por lo tanto la sensibilidad y el respeto que se merecen estas torres vigías, al mismo tiempo que se palìan los efectos de un urbanismo, en ocasiones descontrolado.

\section{LAS TORRES VIGÍAS DE LA COSTA DE MÁLAGA: IDENTIFICACION}

En la actualidad existen repartidas en la costa Malaga mas de una treintena de torres vigias. En el siguiente cuadro puede observarse la importancia que tuvieron en la custodia de la costa, y de las poblaciones proximas:

\section{Costa Occidental:}

Malaga: Torre de las Palomas

Benalmadena: Torre Quebrada, Torre Bermenja, Torre Muelle

Mijas: Torre Nueva de la Cala del Moral, tambien denominada Torre Pesetas, Peseta o Penta Pesetos, Torre vigia de Calaburras, Torre de Cala del Moral o Torrevieja

3. La interpretación que se viene realizando del patrimonio arquitectónico y de sus relaciones con la ciudad histórica cada vez cobran más relevancia en las investigaciones, tal es el caso del Palacio de la Aduana surgido a finales del siglo XVIII, cuando la haza baja de la Alcazaba era una estrecha faja de tierra casi al borde del mar. Su posición en avance, como si se tratase de la proa o la quilla de un barco, la relacionaba directamente con el mar. Los terrenos ganados al mar y el trazado del parque a finales del siglo XIX crearon una paulatina pantalla verde entre el propio edificio y el mar, rompiéndose ese estrecho vínculo. De este modo, la aduana buscó relacionarse con su nuevo entorno, el parque, y la ciudad en la que ha quedado perfectamente integrada. 
Marbella: Torre de las Bovedas, Torre de Rio Real, Torre del Duque, Torre vigia del Lance de las Canas,

Estepona: Torre de Banos o de Casasola, Torre de Guadalmansa, Torre vigia del Padron, Torre vigia del Saladillo, Torre vigia del Velerin, conocida con el sobrenombre de Al - Belerin, Torre de Salavieja o de las Doncellas

Manilva: Torre de la Chullera o de la Culebra

Casares: Torre de la Sal o Salto de la Mora

\section{Costa Oriental:}

Rincon de la Victoria: Torre del Cantal o de los Cantales, Torre de Benagalbon

Algarrobo: Torre Derecha, Torre Ladeada

Velez - Malaga: Torre de Lagos, Torre del Jaral, Torre de Manganeto, tambien conocida, como la Boca del Rio Velez, Torre de Chilches, Torre Moya, denominada en otros documentos como Torre de Benafarafe o Torre Gorda

Torrox: Torre de Gui o del Morche, Torre de Calaceite

Nerja: Torre Macaca, Torrecilla o del Chullo, Torre de Maro, Torre del Rio de la Miel o de Colmenilla, Torre del Pino, Torre de la Caleta

\section{EL RECONOCIMIENTO LEGISLATIVO: DEL DECRETO LEY DE 1949, A LA LEY DE PATRIMONIO HISTÓRICO ESPAÑOL DE 1985}

El conocimiento de la situacion juridica de las torres vigias permite comprender principalmente su estado actual. La primera disposicion administrativa que decidio impulsar su proteccion fue el decreto ley de 22 de abril de 1949, segun el enunciado de su articulo primero: "Todos los castillos de España, cualquiera que sea su estado de ruina, quedan bajo la protección del Estado, que impedirá toda intervención que altere su carácter o pueda provocar su derrumbamiento." En principio esta medida hacía hincapie sobre una realidad que entonces ya era algo mas que evidente, su lamentable estado de conservacion. Sin embargo, la ley no tenía un carácter propositivo en cuanto a mejorar la situación de deterioro físico de estas torres defensivas, sino unicamente de impedir cualquier intervención que pudiera modificarlas, y sobre todo inventariarlas. Teniendo en cuenta lo que contemplaba ese decreto ley, y el hecho de que la ley de Patrimonio de la II Republica de 1933 estuviera vigente durante todo el periodo franquista, pero sin haber incorporado la figura del entorno en su articulado, explica como con el paso del tiempo, y debido a la caótica situación urbanística surgida a partir de los anos 60 del siglo XX, dio como resultado la imagen desastrosa que presentan en la actualidad la mayoria de estas torres vigias. 
El entorno por definición es un espacio estrechamente vinculado con el inmueble, que tiene la finalidad de proteger el ámbito vital en el que culturalmente ha nacido y se ha desarrollado lo que nosotros calificamos como monumento. Dependiendo de la entidad del bien inmueble la situación se complica, entre otras razones, porque el entorno atiende a multiples variables. De este modo, no es lo mismo delimitar un entorno de un bien inmueble que geográficamente abarque todo el casco urbano, que el que se ubica en medio de una calle. En este sentido, el entorno es una herramienta utilisima para conocer el desarrollo urbanístico de la ciudad, y comenzar a percibirla desde otra óptica. En el caso de las torres vigías, las visuales en relación con el paisaje en el que se insertan estos monumentos era un objetivo primoridial, no para garantizar su protección, pues ya lo estaban desde el año 1949, sino su espacio vital.

Cuando la ley de Patrimonio Histórico Espanol entró en vigor, la Disposición Adicional Primera estableció que: "Los bienes que con anterioridad hayan sido declarados histórico - artísticos o incluidos en el Inventario del Patrimonio Artístico y Arqueológico de España pasan a tener la consideración y a denominarse Bienes de Interés Cultural..." Asimismo, la Disposición Adicional Segunda expresa que "Se consideran, asimismo, de Interés Cultural y quedan sometidos al régimen previsto en la presente Ley los bienes a que se refiere el Decreto de 22 de Abril de 1949."

Esta inminente realidad significó sobre todo un choque brutal, ya que la nueva ley contemplaba finalmente la figura del entorno, y los inmuebles acogidos a esta disposición transitoria no lo tenían. Así que debía iniciarse la adaptación de estos monumentos a una nueva situación urbana que había cambiado de manera espectacular, especialmente tras los últimos cuarenta anos desde su declaración, y después de un desarrollo urbanístico sin precedentes en la costa occidental de Málaga. El titulo II De los Bienes Inmuebles de la ley de PHE contiene las pautas para conocer como se contempla la figura del entorno dentro de esta normativa: el art. 14 que se refiere a la definición de inmueble, incluye los elementos que formen parte del mismo o de su entorno...; el art. 17: "En la tramitación del expediente de declaración como bien de interés cultural de un conjunto histórico deberán considerarse sus relaciones con el área territorial a que pertenece, así como la protección de los accidentes geográficos y parajes naturales que conforman su entorno." Quizas este parrafo sea uno de los mas significativos, ya que se introduce la clave para comprender que el Conjunto Histórico no se encuentra aislado, sino que forma parte de una unidad territorial y paisajística, y que como tal precisa de un entendimiento global, y no parcial. En el caso de las torres vigías su especial ubicación en la costa, casi siempre fuera del ambito de actuacion del conjunto historico, le ha perjudicado enormemente, no atendiéndose a los valores patrimoniales que portaba, y sobre todo vulnerándose la percepción de su imagen. 
Por primera vez la le ley reconocía en el art. 18 que: "Un inmueble declarado bien de interés cultural es inseparable de su entorno. No se podrá proceder a su desplazamiento o remoción, salvo que resulte imprescindible por causa de fuerza mayor o de interés social..." Esta definición era un reconocimiento explícito a todos lo bienes de interés cultural, y por la Disposición Adicional segunda, ya mencionada, estas torres gozaban del privilegio, aunque tarde, de obtener un ámbito espacial indisoluble a la propia idiosincrasia del bien.

La motivación de la declaración de los entornos de las torres vigías se sustentan en los siguientes criterios:

- Es un mandamiento de la ley, según lo expuesto anteriormente

- Garantizar su definición espacial

- Garantizar la visualización del inmueble

- Garantizar su conservación, debido a que muchas urbanizaciones han aprovechado la privilegiada situacion de estas torres, lo que ha significado comprometer su integridad física o acelerar el estado de abandono en el que se encontraban

- Cuando la zona ya se encontraba consolidada urbanisticamente es importante establecer algunas cautelas, como la depuración de los letreros o el mantenimiento limpio de la zona

- La obligación de los propietarios de mantener dignamente estos monumentos

\section{PAISAJE Y ENTORNO DE LAS TORRES VIGÍAS: EL PLANEA- MIENTO URBANÍSTICO}

El análisis del planeamiento urbanístico, en relación con estos monumentos, es una de las herramientas que mejor permite conocer los criterios que los redactores han seleccionado para dotar a estas torres de unas ciertas garantias de protección y conservación en los documentos de ordenación urbana. Algunos de estos planeamientos urbanísticos son significativos, tanto por sus aciertos, como por sus carencias.

El PGOU de Benalmadena, aprobado definitivamente en 1990 calificaba como suelo urbano el lugar donde se encontraba la torre, y lo clasificaba como equipamiento. En este documento se echa en falta algunas previsiones para los entornos de las torres vigias. El apartado 2.7 "Protección del Paisaje y del Medioambiente" de dicho documento determina en el subepígrafe 2.7.1.5 que "En el entorno de los núcleos, sectores o edificios de interés histórico - artístico o pintoresco, deberán estudiarse las alturas de la edificación de modo que 
no se afecte a la escala y composición de los conjuntos." Sin embargo, nada de esto parece haberse tenido en cuenta en relación a las torres vigías, pues los tres inmuebles existentes en el término municipal aparecen ahogadas en las edificaciones recientes. Y aunque algunas de las intervenciones arquitectónicas son posteriores a la redacción del planeamiento, lo cierto es que otras son de rabiosa actualidad, y ha hecho caso omiso a la normativa urbanistica.

El caso de Manilva tambien es significativo. El documento urbanistico se aprobo en 1994, siendo su redactor Miguel Angel Graciani Rodriguez, calificándose la torre como suelo urbano, y lo clasifica como zona verde. Sin embargo, resultan bastante escuetos los objetivos en materia de protección contenidos en esta normativa. No hay un reconocimiento expreso al paisaje y a su conexión con la torre, que son elementos indisolubles en la valoración del patrimonio cultural, ni tampoco una lectura integradora del monumento en relación a su territorio costero. Hay que destacar la diferencia que establece el planeamiento entre la arqueología y otros bienes de interés, y si para los yacimientos arqueológicos desarrolla una amplia gama protectora, el epígrafe 13 "Edificios de Interés", resulta poco elaborado, seleccionando diez elementos destacados "por sus valores históricos, culturales o estrictamente arquitectónicos." El n. 3 corresponde a la Torre de Chullera. Para este inmueble define las siguientes pautas, "se prohíbe cualquier actuación destructiva o que altere sensiblemente sus cualidades arquitectónicas." Igualmente, expresa que "los propietarios atenderán adecuadamente a su conservación y mantenimiento," siendo su uso preferente público o privado.

El documento de Casares, donde se encuentra la torre de la Sal o Salto de la Mora, se trata de unas Normas Subsidiarias, aprobadas definitivamente en 1985. Su redactor fue Luis Machuca SantaCruz. En cuanto al tratamiento dado a este inmueble se queda bastante corto, entre otras razones, porque sólo se le identifica como yacimiento arqueológico, evidenciándose el desconocimiento del equipo redactor de que las torres vigías son también monumentos, y por lo tanto requieren otro tipo de atención.

Si echamos la vista atras y nos detenemos en el maravilloso paisaje cultural que emprendieron las torres vigías desde el momento en el que se afianzaron en el territorio, uno de sus valores mas inmdiatos ha sido su integracion tipologica en la costa, adaptandose perfectamente a la llanura, a los espaciosos acantilados. Temboury recogió un importante numero de fotografias, no solo de detalles, sino de conjunto que permite conocer el territorio aún virgen durante los anos 40 y 50 del siglo XX. (Fig. 6 - 8) En esos incontestables paisajes hemos perdido la oportunidad, por el propio desconocimiento del ser humano, unido a una acentuada dejadez, de haber conservado casi intacto uno de los legados paisajísticos mas soprendentes que la mano del hombre ha podido crear. 


\section{LAS TORRES VIGÍAS. ESTRATEGIAS CULTURALES PARA UN VASTO TERRITORIO}

La política de la Junta de Andalucía en materia de cultura ha ido vertebrándose paulatinamente a traves de sus Planes Generales de Bienes Culturales. En el ano 2006 la Direccion General de Bienes Culturales ha trazado una política específica de cara a la conservación de la arquitectura defensiva en Andalucía. Dicho plan se conoce con el sobrenombre de P.A.D.A. Con ella se pretende generar y recabar sensibilidades de cara a rescatar del olvido muchas de estas arquitecturas. En el caso de las torres vigías costeras esta acción tutelar para el 2006 tiene escaso eco, ya que se ha destinado el presupuesto a los castillos, que también forma parte de la arquitectura defensiva. No obstante, es un buen signo que esta línea de intervención en torno a esta tipología arquitectónica en Andalucía se consolide de forma prioritaria, teniendo en cuenta el papel que ésta ha desempeñado en todo el territorio andaluz verso la historia, además de procurar a la sociedad el conocimiento de uno de los patrimonios altamente vulnerados, al mismo tiempo que encierra una riqueza tipológica y paisajística de suma relevancia cultural para nuestra Comunidad Autónoma.

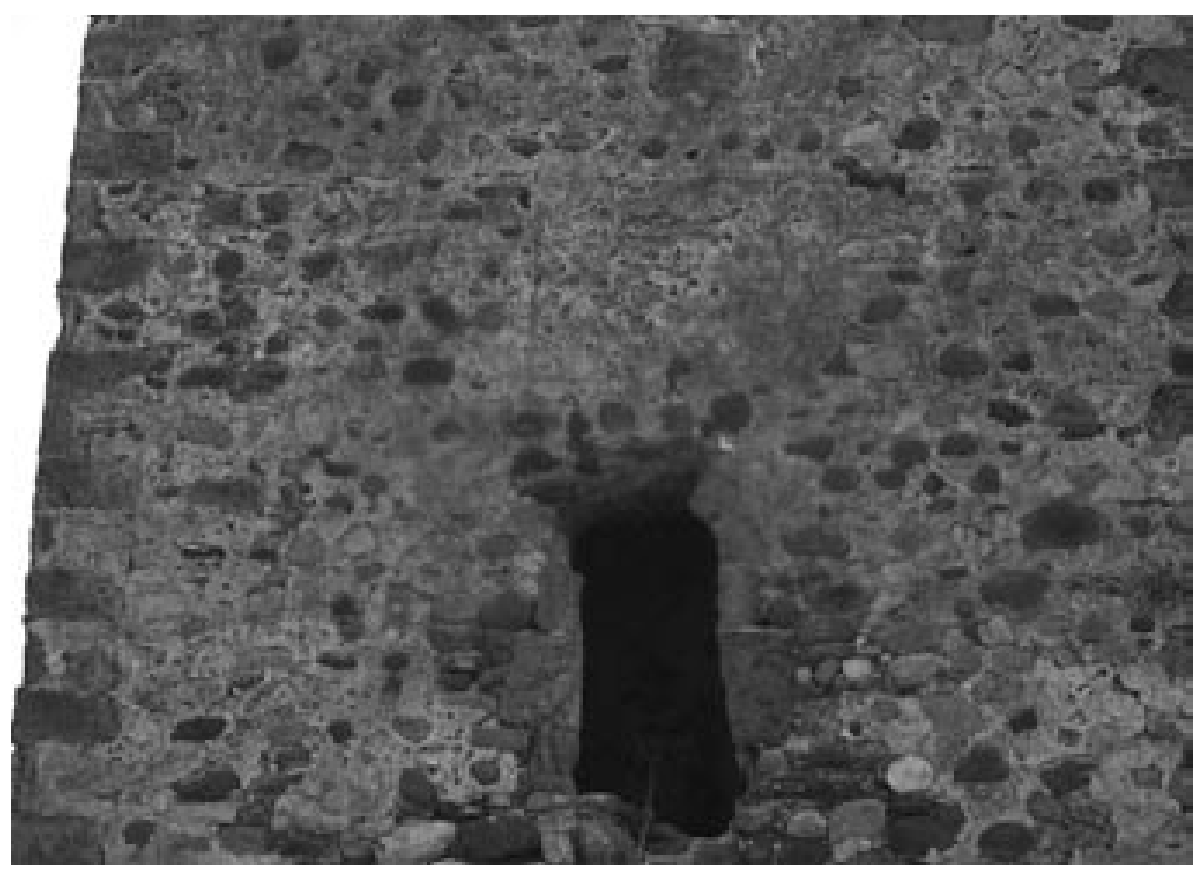

1. Detalle de la Torre de Guadalmansa. Estepona 


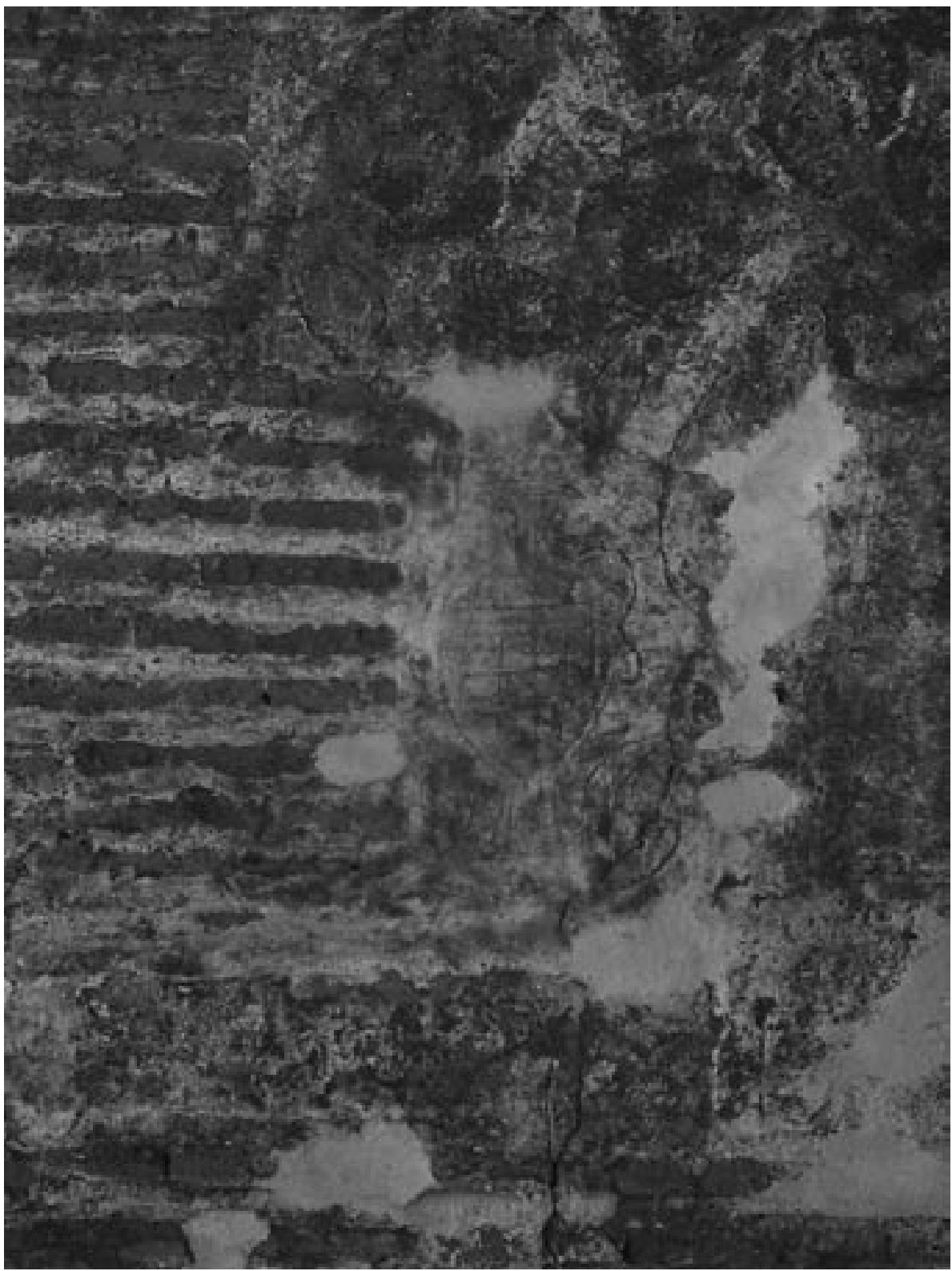

2. Detalle de la Torre Nueva de la Cala del Moral. Mijas 


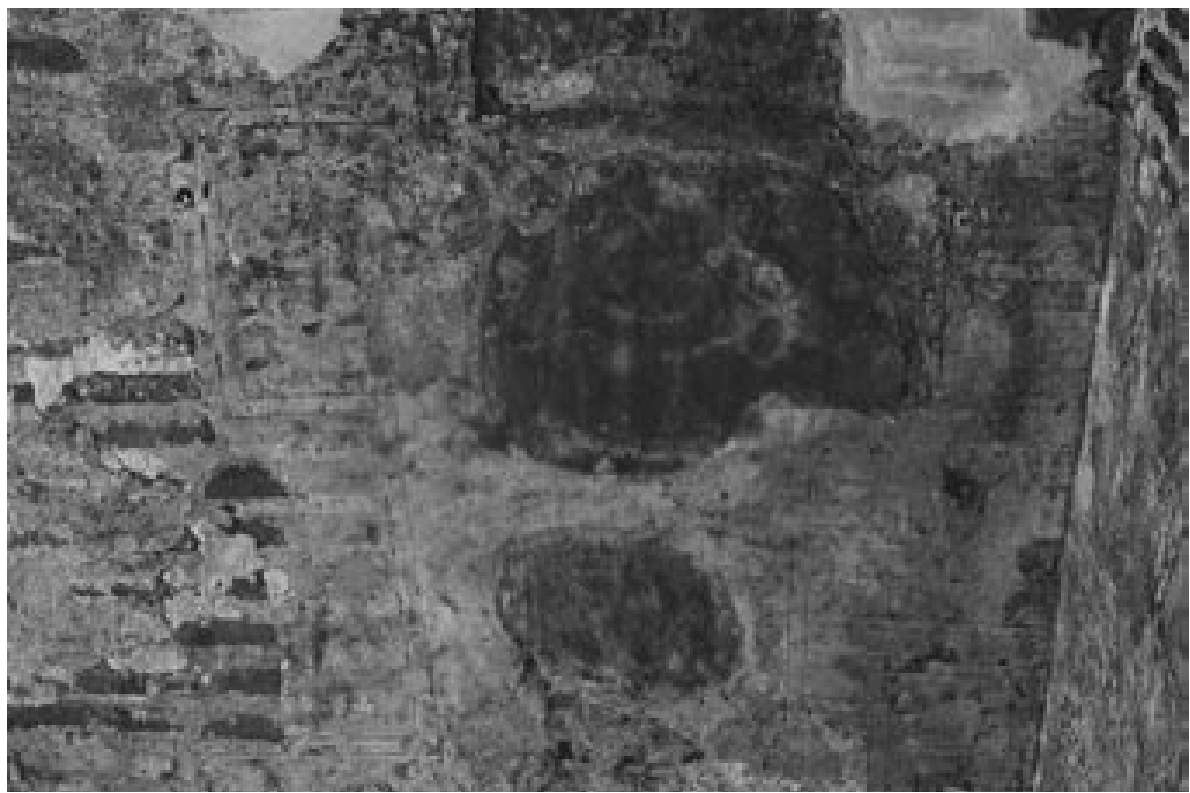

3. Detalle de la Torre Nueva de la Cala del Moral. Mijas

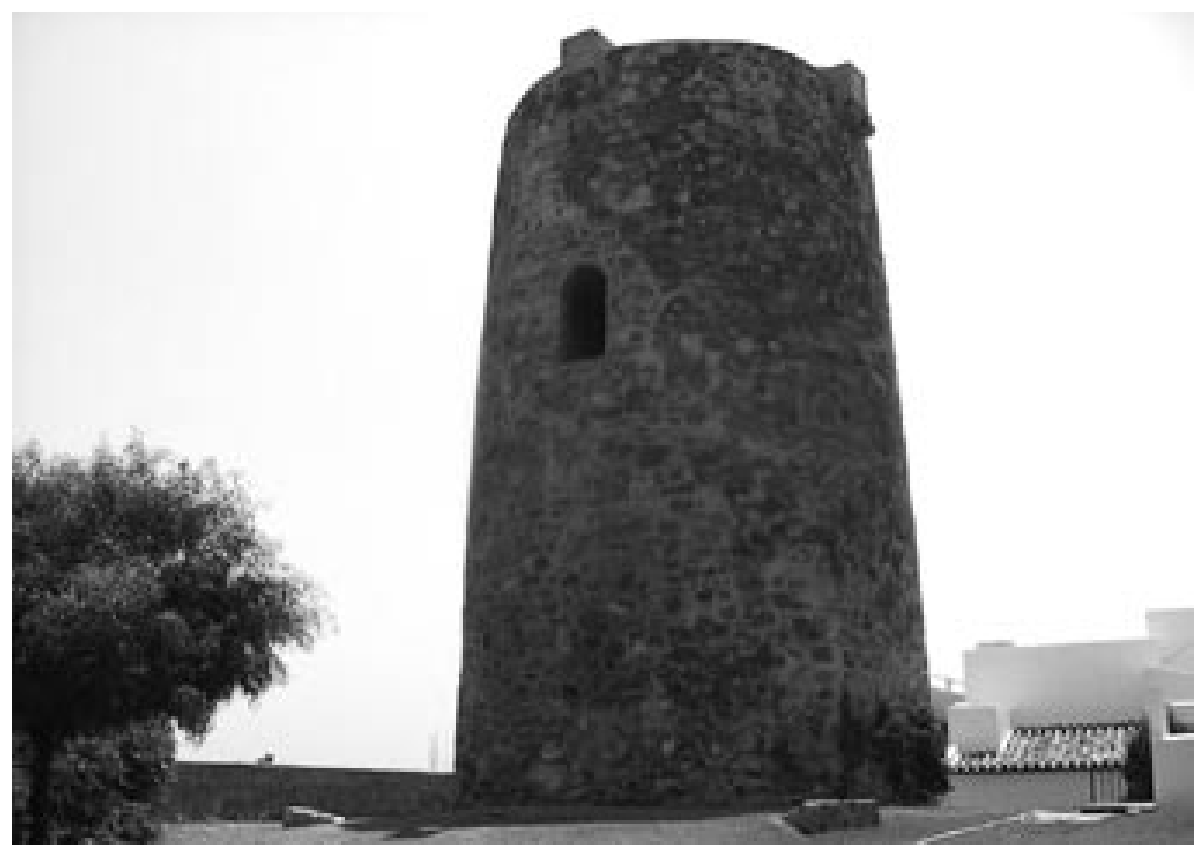

4. Torre vigía de planta circular 


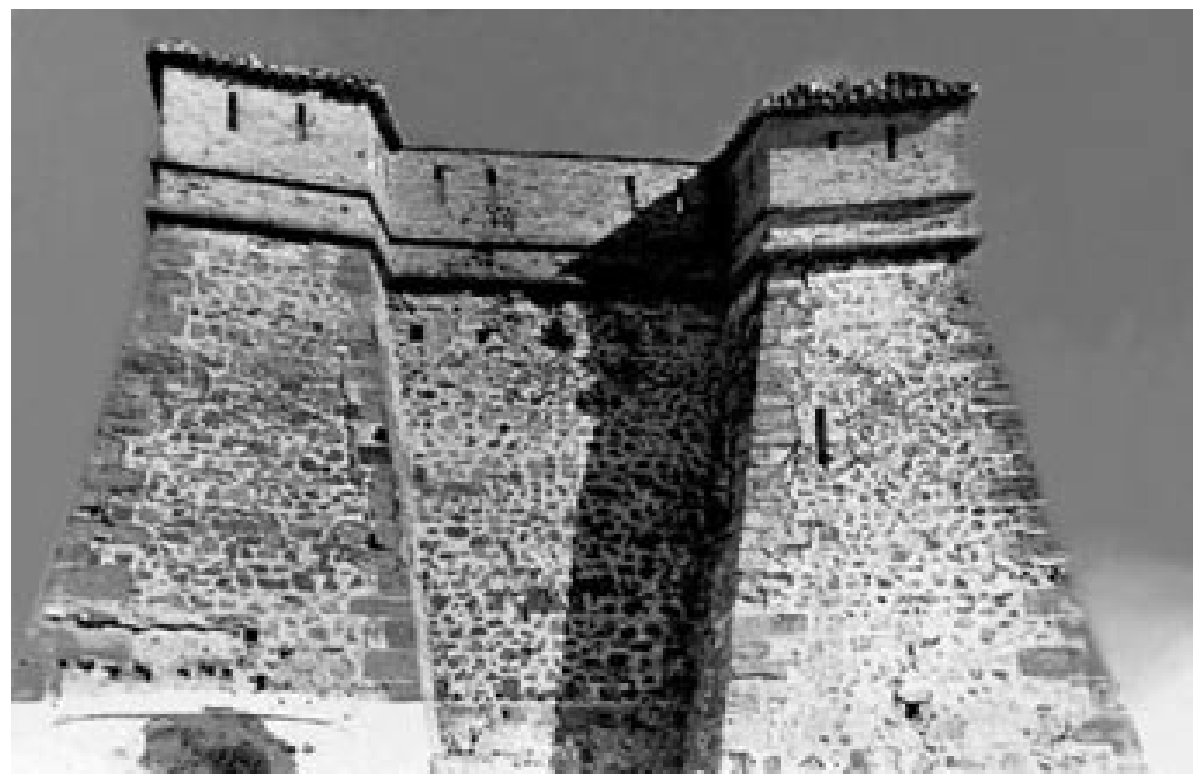

5. Torre vigía de planta de pezuna

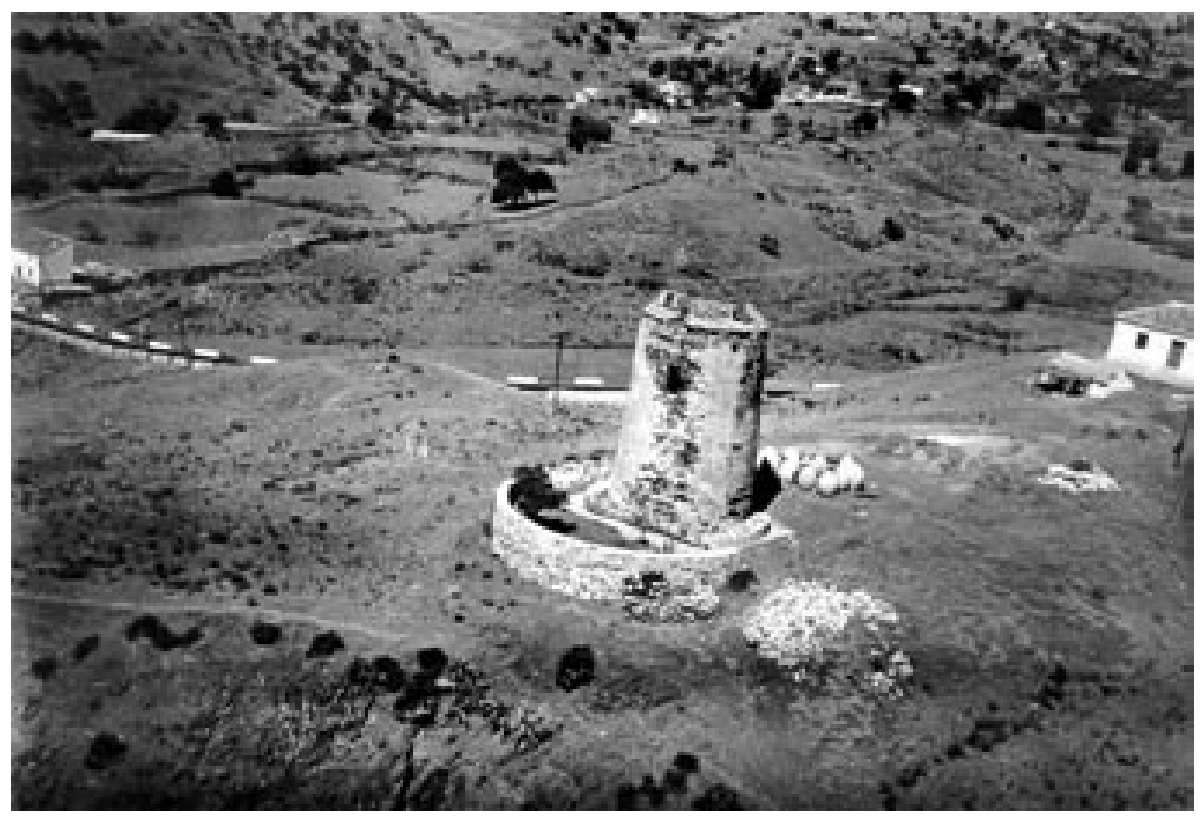

6. Vista aerea de la Torre vigía de Torremuelle. Benalmadena 


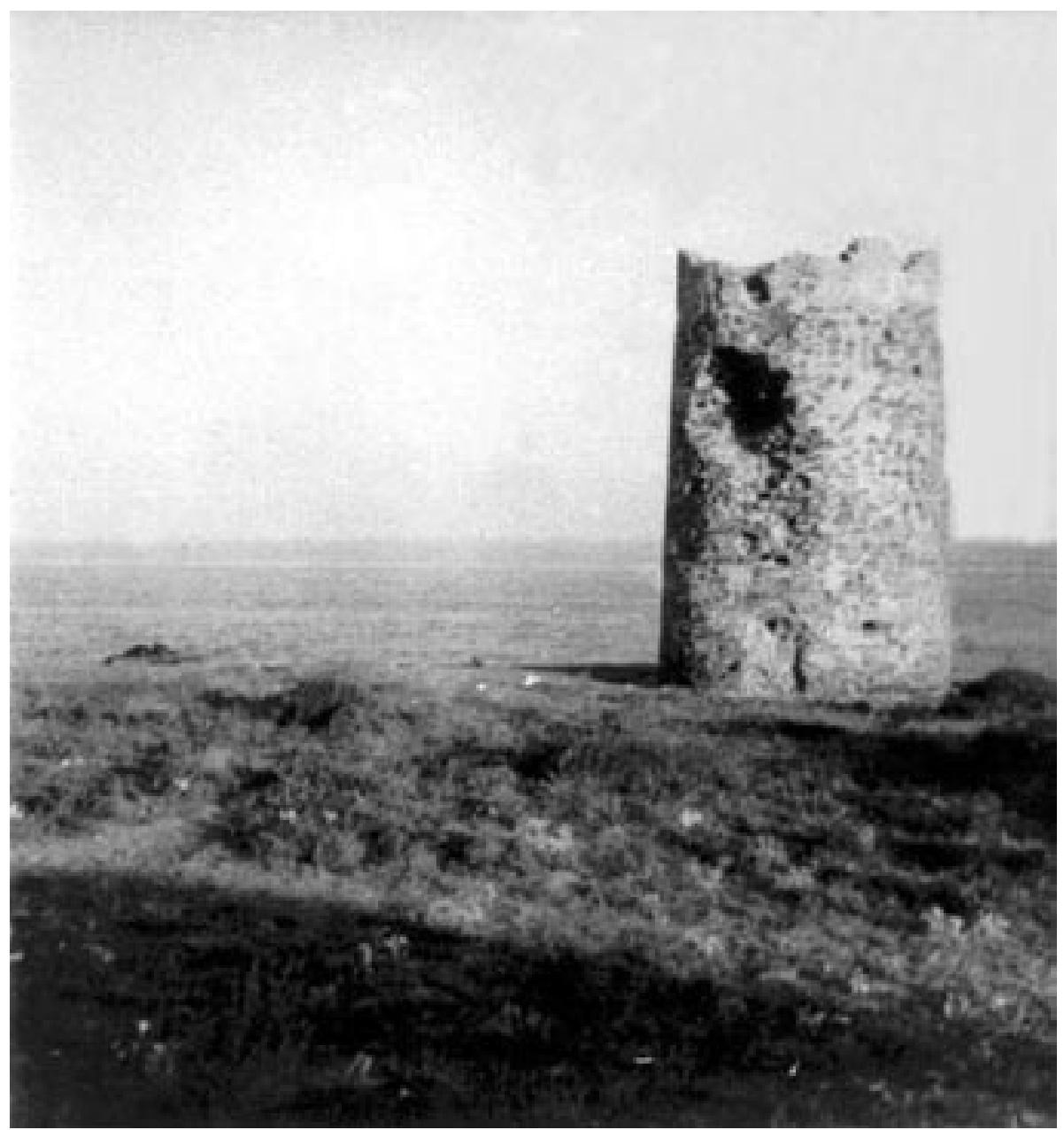

7. Torre vigía de Calahonda. Mijas 


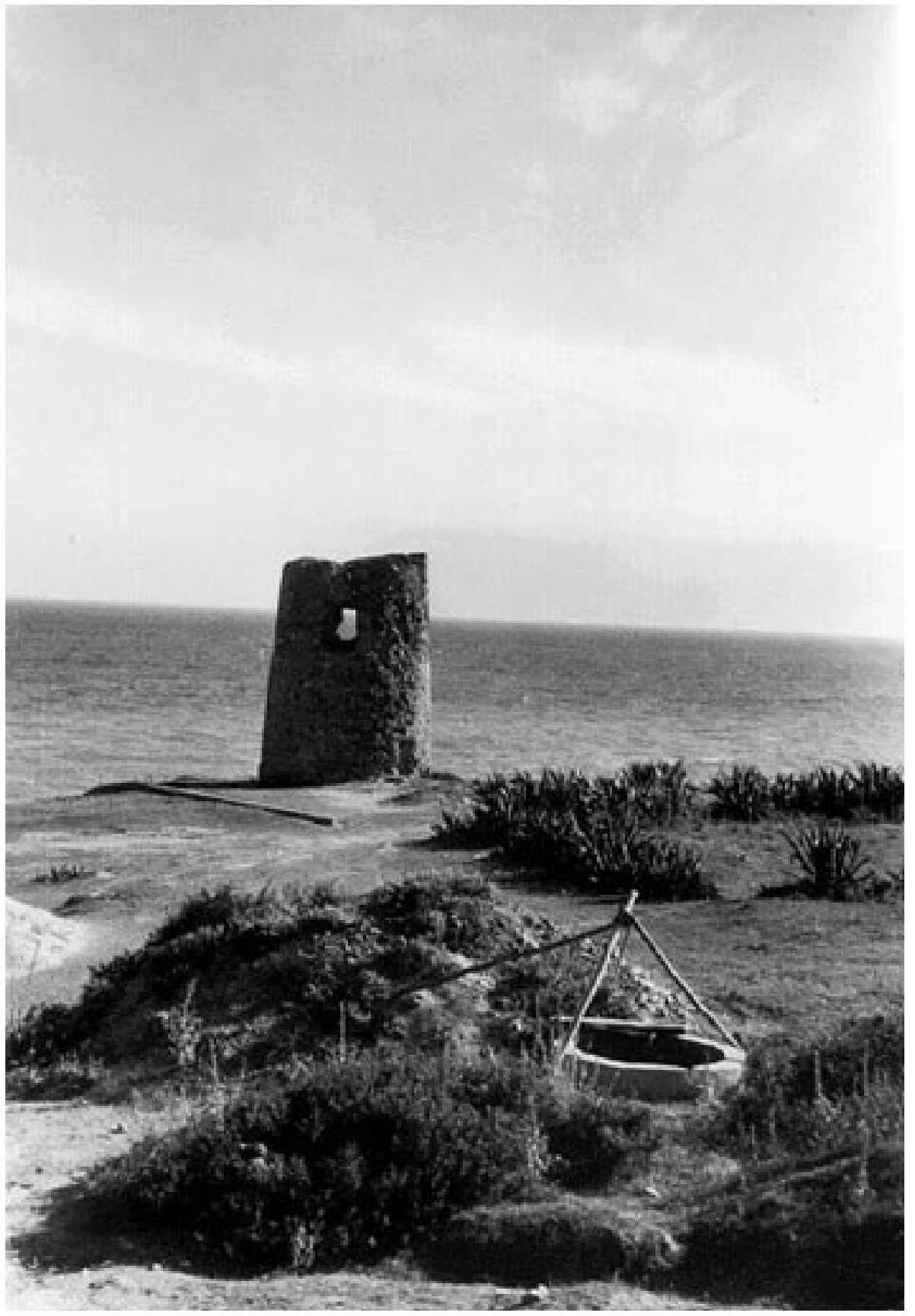

8. Torre vigía de la Chullera. Manilva 
